\title{
Pretreatment of Woven Jute FRP Composite and Its Use in Strengthening of Reinforced Concrete Beams in Flexure
}

\author{
$\operatorname{Tara~Sen}^{1}$ and H. N. Jagannatha Reddy ${ }^{2}$ \\ ${ }^{1}$ Department of Civil Engineering, National Institute of Technology, Agartala, Barjala, Tripura (West), Jirania, Pin 799055, India \\ ${ }^{2}$ Department of Civil Engineering, Bangalore Institute of Technology, K. R. Road, V. V. Puram, Bangalore, Pin 560004, India \\ Correspondence should be addressed to Tara Sen; tarasen20@gmail.com
}

Received 30 May 2013; Revised 18 August 2013; Accepted 27 August 2013

Academic Editor: Shaikh Faiz Uddin Ahmed

Copyright (c) 2013 T. Sen and H. N. J. Reddy. This is an open access article distributed under the Creative Commons Attribution License, which permits unrestricted use, distribution, and reproduction in any medium, provided the original work is properly cited.

\begin{abstract}
Environmental awareness motivates researchers worldwide to perform studies of natural fibre reinforced polymer composites, as they come with many advantages and are primarily sustainable. The present study aims at evaluating the mechanical characteristics of natural woven jute fibre reinforced polymer (FRP) composite subjected to three different pretreatments, alkali, benzyl chloride, and lastly heat treatment. It was concluded that heat treatment is one of the most suitable treatment methods for enhancing mechanical properties of jute FRP. Durability studies on Jute FRP pertaining to some common environmental conditions were also carried out such as effect of normal water and thermal aging on the tensile strength of jute FRP followed by fire flow test. The heat treated woven jute FRP composites were subsequently used for flexural strengthening of reinforced concrete beams in full and strip wrapping configurations. The study includes the effect of flexural strengthening provided by woven jute FRP, study of different failure modes, load deflection behavior, effect on the first crack load, and ultimate flexural strength of concrete beams strengthened using woven jute FRP subjected to bending loads. The study concludes that woven jute FRP is a suitable material which can be used for flexural upgradation of reinforced concrete beams.
\end{abstract}

\section{Introduction}

A structure is designed for a specific life span, and depending on the nature of the structure, its purpose, and its usability, its design life varies. For a domestic building, this design life could be thirty to forty years, whereas for a public building, it could be fifty to sixty years. Deterioration in concrete structure is a major challenge faced by the infrastructure and bridge industries worldwide. The deterioration can be mainly due to environmental effects, which include corrosion of steel, gradual loss of strength with aging, repeated high intensity loading, variation in temperature, freeze-thaw cycles, contact with chemicals and saline water and exposure to ultraviolet radiations, and also deterioration due to exposure to an aggressive environment and accident events such as earthquakes. That is why reinforced concrete structures often have to face modifications and improvements of their performance during their service life. When possible, it is often better to repair or upgrade the structure by retrofitting which is prestrengthening a structure before its failure. The most common and advanced material used worldwide for structural strengthening is FRP (fibre reinforced polymer) composites, which are used for the strengthening purposes be it in flexure or shear or the ductility parameter or even confinement, and is successfully used all over the world the said purpose [1-4]. FRPs help to increase strength and ductility without excessive increase in stiffness and self weight, as they are very light materials. FRPs have various advantages such as, high strength, low weight, corrosion resistance, high fatigue resistance, easy and rapid installation and minimal change in structural geometry, and better mechanical and chemical performance. Beams are the critical structural members subjected to bending, torsion, and shear, and they are one of the most important load carrying elements in a structural system. Therefore, extensive research works are being carried out throughout the world on the retrofitting of concrete beams with externally bonded FRP composites. The most common FRP materials used for retrofitting 
and rehabilitation of concrete members include carbon, glass, and aramid FRPs. It has been experimentally proved that when concrete beams and columns are retrofitted with carbon-fibre-reinforced polymer (CFRP) composites, then there is an enhancement in the flexural strength, shear strength, and torsional strength [5-9]. Also glass fibre reinforced polymer (GFRP) composites have been very successful in improving the flexural strength, shear strength, torsional strength, and so forth of concrete structures. [10-12]. All these FRPs mentioned above are artificial fibres or man-made fibres, which involve large manufacturing and production units with high processing costs. One of the main disadvantages of using man-made fibres as FRPs for strengthening is that beams or columns strengthened with FRP can fail in a brittle manner due to FRP debonding or FRP rupture, at the FRP-concrete interface. This type of brittle failure is very significant and common when carbon FRP or glass FRP materials are used for strengthening. FRPs are a major source of $\mathrm{CO}_{2}$ emissions, most of which arise during their processing and manufacturing. FRPs use large amounts of energy for their production and transport, this is known as the "embodied energy" of the material. Most of this energy is produced by the burning of fossil fuels, which increases the amount of carbon dioxide $\left(\mathrm{CO}_{2}\right)$ in the atmosphere. Crop-derived materials can be used in making FRPs, which have performance attributes that can improve the "in-use" energy profile of buildings and cut down the inherently embodied energy. The present trend of using bio or crop or plant based products for FRP fabrication has been influenced by a number of factors, including increased environmental and health concerns, more sustainable methods of manufacturing and reduced energy consumption, supporting a desire for lighter weight structures, the use of sustainable material in building constructions, and the use of sustainable materials and green material for manufacturing of FRPs. A natural-based material can be defined as a product made from renewable agricultural and forestry feedstock, including crops and crop by-products and its residues. Materials from renewable resources are being sought to replace not only the reinforcement element but also the matrix phase of composite materials, thereby alleviating some of the sustainability issues associated with using synthetics in composites. The widespread use of agricultural crops in construction and the building industry would greatly reduce the impact of artificial construction material use, since FRPs are extensively used worldwide in various civil and mechanical engineering divisions. These factorial considerations combine to provide a substantial environmental benefit to the use of crop-based materials in the making of FRPs. Natural fibres are a good substitution as reinforcement for composite products in place of the customary synthetic fibres such as E glass and they are being researched extensively for their suitable applications [13-17]. It is estimated that there are about 2.3 million tonnes of glass fibres devoted to various applications around the globe so there are a number of opportunities for natural fibres to be used in place of existing glass fibres. Natural fibres have several advantages over glass fibre such as low density, low cost, high toughness, acceptable specific strength properties, good thermal properties, low embodied energy, reduced tool wear, and reduced irritation to the skin and respiratory system, and they also have a low energy requirement for processing and they are also biodegradable or recyclable depending on the selected matrix [18-20]. Further market penetration of natural fibre composite will occur only when their production can be rendered cost-effective and competitive to the present injection-molded thermoplastics used in many branches of science and engineering. Also, plant fibres are hydrophilic in nature due to attraction/interaction between the hydroxyl groups of fibre components and water molecules. The hydrophilic nature of plant fibres often results in poor compatibility with hydrophobic polymer matrices. Therefore, it becomes necessary to modify the surface of plant fibres for aiding in better adhesion between fibre and matrix. In this study, we have carried out and compared various treatment methods such as alkalization, benzoylation, and thermal treatment for surface modification and its corresponding effect on the properties of woven jute fibre reinforced polymer composites along with three durability studies, which are effect of normal water on woven jute FRP, effect of thermal aging on woven jute FRP, and fire flow test on woven jute FRP, were all carried out and analysed. The applications of modified woven jute fibre reinforced polymer composite in improving the flexural capacity of reinforced concrete beams and its suitability was evaluated as a new alternate reinforced polymer composite material used for structural strengthening. The type of concrete failure aided by strengthening the reinforced concrete with woven jute FRP composite was analysed pertaining to failure modes, ductility improvement, load-deflection behaviour, ultimate flexural strength, first crack load, and so forth.

\section{Review of Plant Fibres}

Natural fibres, often referred to as vegetable fibres, are extracted from plants and are classified into three categories, depending on the part of the plant they are extracted from, fruit fibres such as oil palm fibres, bast fibres such as jute fibres, and leaf fibres such as sisal fibres. Nowadays, there is a demand for these natural fibres to be used as reinforcement in polymer matrices. In recent years, there has been increasing interest in the replacement of fibreglass in reinforced plastic composites by natural fibres such as kenaf, oil palm, ramie, sisal, coir, and jute. Jute fibres are bast fibres, and are one of the strongest bast fibres, and it withstands rotting very easily. Jute is the most common agricultural fibre. The fibres of jute are nonabrasive, exhibit moderately higher mechanical properties, and are abundantly available exclusively in Bangladesh, India, Thailand, and also in some parts of Latin America. Researchers have shown that suitable pretreatments of jute yarn can lead to an improvement in its mechanical properties and that jute fibre composites have shown immense potential in terms of its mechanical characteristics [21-30]. The research concerning kenaf plastic composite is also growing tremendously along with the industry's and government's high demand for producing nonpetroleum-based materials. Several treatments have been proposed and used to improve interlaminar bonding of kenaf fibre composites. The fibre 
has been mainly used in rope, twine, coarse cloth, and paper. However, nowadays, there is demand for this fibre to be used as a reinforcement for polymers. Kenaf fibres exhibit low density, nonabrasiveness during processing, high specific mechanical properties, biodegradability, and so forth. Recently, kenaf is being used as a raw material alternative to wood in pulp and paper industries for avoiding destruction of forests, and also it is used as nonwoven mats in the automotive industries, textiles, fibreboard and is also extensively being employed as fibre reinforcement to composites, since it shows promise [31-36]. Sisal too is a highly resistant and rigid natural fibre, mainly used in applications ranging from manufacturing of ropes and yarns for ropes and carpets to different textiles and handicrafts. Sisal fibres are majorly cultivated in Tanzania, Madagascar, Brazil, India, and so forth. They are extracted from the sisal plant leaves in the form of long fibre bundles. From a $100 \mathrm{~kg}$ of sisal leaves about $3.5 \mathrm{~kg}$ extractable fibre is obtained. These fibres have been used as a reinforcement in polymer composites and were characterized mechanically by various researchers. The sisal fibre composites have shown high elastic modulus and tensile strength which could be further improved by surface modifications [37-41]. A lot of research works have been conducted on alternative new fibres such as oil palm fruit bunch fibres. Oil palm biomass is a natural waste product, and hence, available at a minimal cost. Malaysia is one of the leading producers of palm oil. Lignocellulosic fibres can be extracted from the trunk, frond, fruit mesocarp, and empty fruit bunches of oil palm trees. Empty fruit bunches are the fibrous mass left behind after separating the fruits from sterilized fresh fruit bunches. Fibre modifications and coupling agents could be considered for the optimization of the interface, and for the improvement of their properties [42-46]. Fibres of ramie too have shown very high tensile strength and the tensile strength, of ramie is approximately equal to that of glass fibre. Hence, ramie fibre composites have been extensively researched upon for their strong mechanical properties with added environmental benefits. The effect of different ramie fibre surface-treatment methods including silane treated, and alkali treated on the mechanical properties and thermal properties of ramie fibre composites are also being researched upon, for additional strength improvements $[47,48]$. Even coir fibre is an important lignocellulosic fibre obtained from coconut trees, is a very cheap and ecofriendly material which is friendly to the environment, and grows extensively in tropical countries. Coir fibres have many advantages like low density, lower cost, availability, higher lignin content, low elastic modulus, and high elongation at break. Coir fibres too are being considered as a reinforcement in polymer composites by various researchers, since their mechanical properties can be improved by various chemical and physical treatment processes and because of them being natural, resulting in several environmental benefits [4954]. Although various positive and enhanced mechanical characterizations have been underway and yielded positive results with natural fibre composites, also pertaining to their use in various crop industry, textile engineering, mechanical engineering, agricultural engineering, and so forth, very scare research has been devoted to the use of natural fibres as reinforcements in composites, to be used as a strengthening material for structural strengthening. In order to evaluate the effectiveness of FRP materials which uses natural fibres as their reinforcements, to be used as a strengthening material, it might be necessary to investigate the mechanical issues of these FRPs as well as its effect on the various strength parameters of concrete structures simultaneously. This study investigates the mechanical property of the jute fibre FRP with suitable pretreatments using alkali treatment, which is a very commonly established treatment method, followed by benzyl chloride treatment, and lastly heat treatment, which has shown promise in case of the treatment of woven fabrics or yarns, followed by evaluating the effectiveness of flexural strengthening provided by woven jute FRP on the reinforced concrete beams.

\section{Pretreatment and Characterization of Jute FRP Composite}

3.1. Materials. The woven jute was collected from Extra Weave Private Ltd, Cherthala, Kerala, India. All other chemicals used for the fabrication of the natural woven jute FRP composite for its mechanical characterisations and structural strengthening, such as MBrace saturant, which consists of Part A epoxy resin and Part B hardener, were also collected and utilized. Strengthening of the RC beams with FRP composite wrapping using natural jute FRP composite was carried out with the help of chemicals such as concresive 2200 and MBrace primer in conjunction with the MBrace saturant (epoxy-rein-hardener system) were all obtained suitably for the said purpose.

3.2. Pretreatment of Jute Fibres. The chemical treatment of fibre is aimed at improving the adhesion between the fibre surface and the polymer matrix by modifying the fibre surface and the fibre strength. It also reduces the water absorption capacity of the fibre and helps in improving the mechanical properties. Following are the different pretreatments carried out. The woven jute mats were cut into the size required for flexural strength test as per ISO 14125:1998 and tensile strength test as per ISO 527-4:1997(E), and then, the various pretreatments were carried out. Some samples were left untreated as controlled samples for comparison study purpose.

3.2.1. Alkali Treatment. Alkaline treatment is one of the most commonly used chemical treatment procedures, for treating natural fibres when used as reinforcements in thermoplastics and thermosets. The important modification done by alkaline treatment is the disruption of hydrogen bonding in the network structure, thereby increasing surface roughness. This treatment removes a certain amount of lignin, wax, and oils covering the external surface of the fibre cell wall. Addition of aqueous sodium hydroxide $(\mathrm{NaOH})$ to natural fibre promotes the ionization of the hydroxyl group to the alkoxide. Thus, alkaline processing directly influences the cellulosic fibril, the degree of polymerization, and the extraction of lignin and hemicellulosic compounds. It is reported that alkaline treatment has two effects on the fibre: it increases surface 


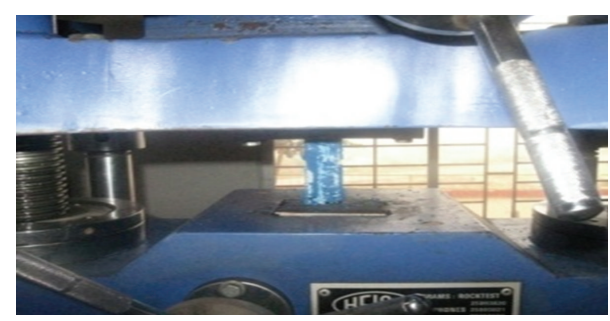

(a)

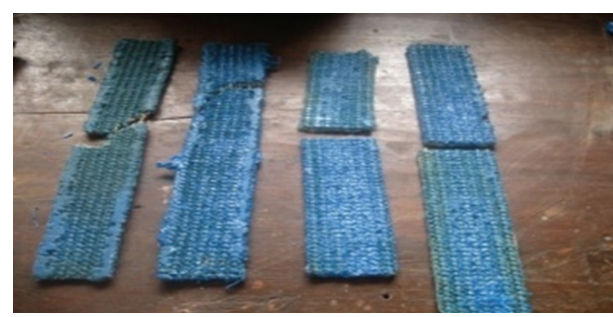

(b)

FIgURE 1: (a) Tensile testing; (b) tensile fracture samples of woven jute FRP.

roughness resulting in better mechanical interlocking and it increases the amount of cellulose exposed on the fibre surface, thus increasing the number of possible reaction sites. Consequently, alkaline treatment has a lasting effect on the mechanical behaviour of natural fibre, especially on fibre strength and stiffness. Woven jute fibre mats in deemed sizes were immersed in $4 \% \mathrm{NaOH}$ solution at room temperature. Then, they were removed from the $\mathrm{NaOH}$ solution and then washed several times with fresh water to remove any $\mathrm{NaOH}$ sticking to the surface, followed by neutralisation with dilute acetic acid. Finally, these woven jute fibre mats were washed again with distilled water, ensuring that a final $\mathrm{pH}-7$ was maintained. The fibre mats were then dried at room temperature for 48 hours followed by oven drying at $50^{\circ} \mathrm{C}$ for 24 hours.

3.2.2. Bezoylation Treatment. Benzoylation is an important transformation in organic synthesis. Benzyl chloride is most often used in fibre treatment. Benzyl chloride includes benzyl $\left(\mathrm{C}_{6} \mathrm{H}_{5} \mathrm{C}=\mathrm{O}\right)$ which is attributed to the decreased hydrophilic nature of the treated fibre and improved interaction with the hydrophobic polymer matrix. Woven jute fibre mats in deemed sizes were immersed in $10 \% \mathrm{NaOH}$ solution agitated with benzyl chloride. This mixture was kept for 15 minutes. After that, the fibre mats were removed from the mixture of $\mathrm{NaOH}$ and benzyl chloride and washed thoroughly with normal water. Then, these wet fibre mats were dried thoroughly using filter paper (white paper). Then, they were soaked in ethanol for 1 hour to remove any benzyl chloride sticking to their surfaces. Finally, the fibre mats were washed thoroughly with water and then dried in the oven at $40^{\circ} \mathrm{C}$ for 48 hours.

3.2.3. Heat Treatment. The mechanical treatment in the form of heat treatment was carried out in the following manner. Woven jute fibre mats in deemed sizes were placed into the oven at $50^{\circ} \mathrm{C}$ for 48 hours. After that, these samples were kept in an air tight chamber so that atmospheric moisture could not be absorbed by these samples. Basically, the raw fibres when exposed to atmosphere absorb moisture, and this moisture which gets accumulated in the fibres requires to be eliminated. This elimination of the moisture from the fibres can be attained by the process of heat treatment. Heat-treated composites of natural textile or fabrics have higher strength than untreated composites of natural jute fibre textiles.

3.3. Fabrication of Composites. A plastic bit mould with suitable dimensions was used for casting the woven jute composite sheets. The usual hand lay-up technique was used for preparation of the samples. A calculated amount of epoxy resin and hardener ratio of $10: 4$ by weight was thoroughly mixed with gentle stirring to minimize air entrapment. For quick and easy removal of composite sheets, a mould releasing agent was used, which was silicone grease. Electrical insulating paper was put underneath the plastic bit mould, and silicone grease was applied at the inner surface of the mould. After keeping the mould on the insulating sheet, a thin layer ( $\approx 2 \mathrm{~mm}$ thickness) of mixture of epoxy and hardener was poured. Then the woven jute fibre mats (both pretreated and untreated) were separately distributed on the mixture on different moulds. The remaining mixture was then poured into the mould on top of the fabric mats. Care was taken to avoid formation of air bubbles. Pressure was then applied from above to the mould, and with this pressure still on top of the composite sheet, it was allowed to cure at room temperature for $48 \mathrm{hrs}$. After $48 \mathrm{hrs}$, the samples were taken out from the mould and kept in an air tight container for further experimentation.

3.4. Mechanical Testing. Two mechanical tests were performed for all the samples of woven jute fibre composites, the two tests were tensile strength test, and flexural strength test. All treated FRP composites were subjected to the above mentioned two tests. During the tensile test, an uniaxial load was applied through both the ends of the specimen, using suitable jaws as an attachment to the UTM. The tensile test was performed in the universal testing machine (UTM) which was HEICO digital universal testing machine, and results were obtained digitally with the digital data acquisition system, which aided us in calculating the tensile strength of composite samples. The tensile strength test for jute FRP composites was done in accordance to ISO 527-4:1997(E), as jute falls under the category of Type-2 materials. All the results were taken as an average value of 5 samples each. Figure 1 shows the woven jute FRP composite under tensile load conditions and the tensile fractures in the composite samples. Jute FRP composites displayed both diagonal and straight types of fracture (fracture exactly perpendicular to the direction of the woven jute fabric). All these failure modes are accepted modes of tensile fracture in accordance to ISO 527-4:1997(E) and ISO 527-5:1997(E). The flexural strength of a composite is a 3-point bend test, which generally promotes failure by interlaminar shear. This test was conducted as per ISO 14125:1998 standard using 
TABLE 1: Tensile strength property of pretreated and untreated (controlled) woven jute FRP composites.

\begin{tabular}{|c|c|c|c|c|}
\hline Mechanical property & $\begin{array}{l}\text { Alkali treated } \\
\text { jute fabric FRP }\end{array}$ & $\begin{array}{l}\text { Benzoylated treated } \\
\text { jute fabric FRP }\end{array}$ & $\begin{array}{l}\text { Untreated jute } \\
\text { fabric FRP }\end{array}$ & $\begin{array}{c}\text { Thermally/heat } \\
\text { treated jute fabric FRP }\end{array}$ \\
\hline Tensile strength (MPa) & 83.836 & 101.534 & 148.603 & 189.479 \\
\hline Tensile modulus (MPa) & 15000 & 13500 & 16000 & 32500 \\
\hline Flexural strength $(\mathrm{MPa})$ & 158.631 & 97.572 & 183.932 & 208.705 \\
\hline Flexural modulus (MPa) & 2750 & 2500 & 4250 & 4500 \\
\hline
\end{tabular}

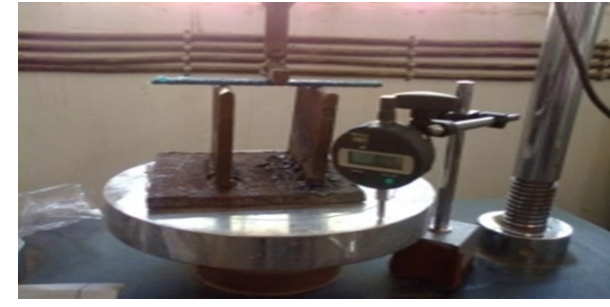

(a)

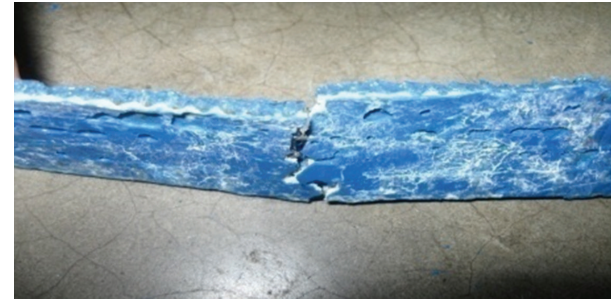

(b)

FIGURE 2: (a) Flexural testing; (b) flexural fracture of woven jute FRP.

a load cell of high sensitivity. The loading arrangement is shown in Figure 2. Since jute belongs to Class II Type material, hence, all the restrictions of the specimen dimensions for flexural testing were followed, as per the code ISO 14125:1998. After the flexural failure occurred, all the specimens of the FRP composites showed a single line fracture (perpendicular to the plane of the composite direction). Also both the tensile modulus of elasticity and the flexural modulus were found out for all the samples of woven jute FRP composites subjected to different pretreatments were also obtained. The modulus of elasticity, which is equal to the Young's modulus, is a material property that describes its stiffness and is therefore one of the most important properties of solid materials. Mechanical deformation puts energy into a material. This energy is stored elastically or dissipated plastically. The way a material stores this energy is summarized in the stressstrain curves. Stress is defined as force per unit area and strain as elongation or contraction per unit length. When a material deforms elastically, the amount of deformation likewise depends on the size of the material, but the strain for a given stress is always the same, and the two are related by Hooke's Law (stress is directly proportional to strain). Moduli of elasticity, both tensile and flexural modulus were obtained since these parameters play a vital role in evaluating the mechanical characteristics of a material. The tensile strength, tensile modulus (modulus of elasticity), flexural strength, and flexural modulus are presented in Table 1, and a graphical comparison of the tensile and flexural behavior of woven jute FRP composites, subjected to different pretreatments and no treatment (i.e., controlled samples) is presented in Figure 3.

\section{Durability Study of Woven Jute FRP Composite}

While most of us have general sense of what the term "durability" means, is not easily defined in the context of infrastructure materials, and numerous definitions have been proposed in the literature. In the current educational module durability, is defined on the basis of a definition offered by Karbhari et al. [55] as the ability of an FRP element "to resist cracking, oxidation, chemical degradation, delamitation, wear, and/or the effects of foreign object damage for a specified period of time, under the appropriate load conditions, under specified environmental condition." The available data on the durability of FRP materials is somewhat limited and can thus appear contradictory in some cases. This is due to the many different forms of FRP materials and fabrication processes currently used. Furthermore, FRPs used in civil engineering applications are substantially different from those used in the aerospace industry, and hence their durability cannot be assumed to be the same. All engineering materials are subject to mechanical and physical deterioration with time, load, and exposure to various harmful environments. When FRPs are used as reinforcement or are used for the strengthening of reinforced concrete structures, then they can be expected to be exposed to a variety of potentially harmful physical and chemical environments and can undergo potential damage if used improperly in a number of harmful environments. Here, durability of woven jute FRP composite was evaluated under three most common environmental conditions of civil infrastructure.

4.1. Effect of Normal Water. The mechanical properties of thermoset resin matrix composite materials are affected when exposed to wet environments. The absorbed water causes matrix plasticization and or interface degradation. The effect of water environment on moisture $\left(\mathrm{H}_{2} \mathrm{O}\right)$ absorption characteristics of woven jute epoxy composite material has been investigated by the measurement and analysis of percentage moisture content, thickness swelling, and effect of water on the tensile strength property of woven jute FRP composite. Firstly, the composites were weighed and their thicknesses were measured. Normal water was then collected and heated (till bubbles started appearing) to $100^{\circ} \mathrm{C}$ along 

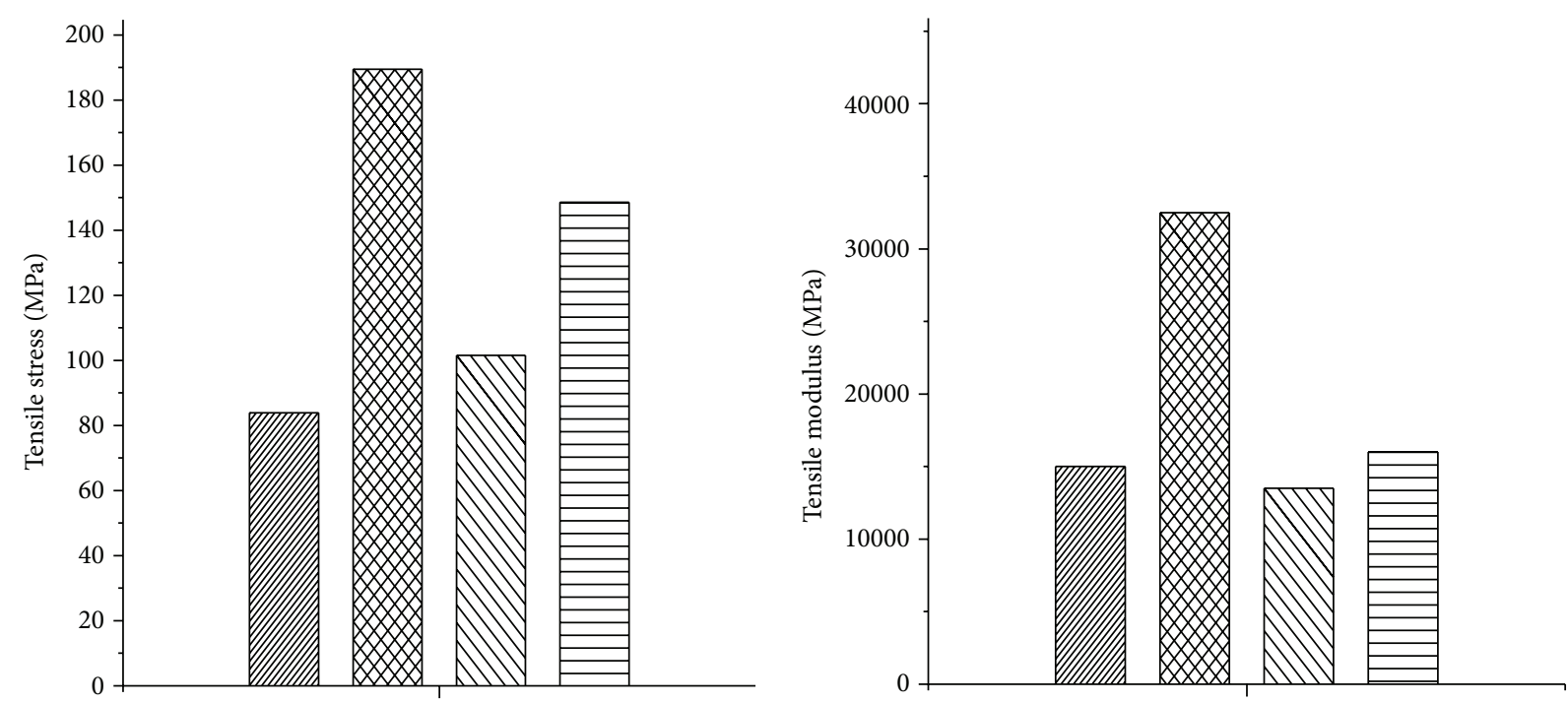

(a)
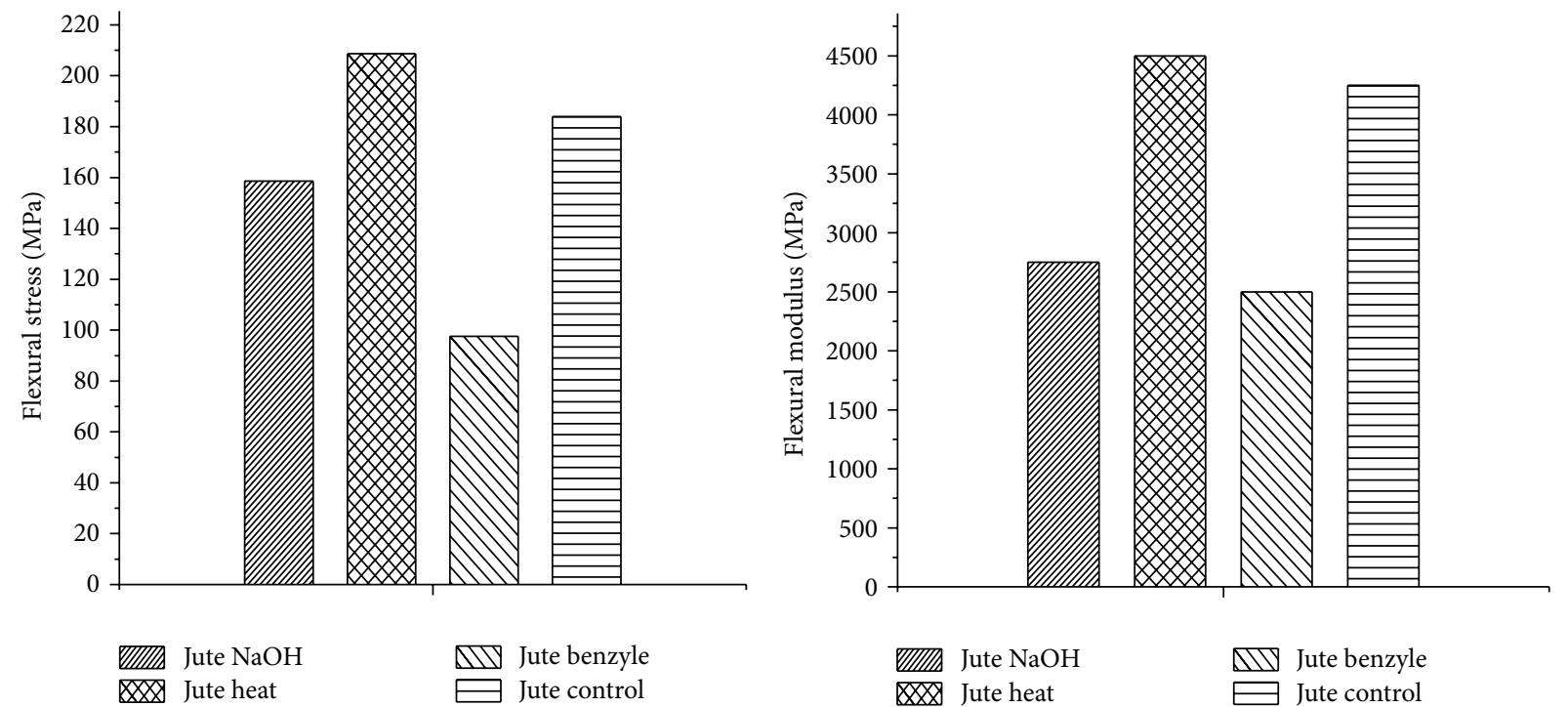

(b)

FIGURE 3: (a) Tensile behaviour of jute FRP composite, woven jute being subjected to different pretreatments; (b) flexural behaviour of jute FRP composite, woven jute being subjected to different pretreatments.

with the composites for $30 \mathrm{~min}$, then the composites were removed from the hot water and wiped with cotton and then weighed again and their thicknesses were measured. The relative mass change of the epoxy in the specimens under study was expressed as a percentage obtained using the expression: Moisture content $=$ (weight of soaked specimen - weight of dry specimen)/weight of dry specimen. Thickness swelling index was also measured by measuring the thickness of the composites before and after boiling. Lastly, tensile strength tests were carried out on these composite samples. It was observed that the moisture content percent was $6.6 \%$ and thickness swelling was $8.9 \%$, but the tensile strength increased from $189.48 \mathrm{MPa}$ under dry conditions to 213.42 MPa under wet conditions. The hygrothermal effects on the woven jute FRP could be viewed as a result of two mechanisms. Firstly, at the macroscopic level, the expansion of the matrix due to absorption of water may cause tensile stresses in the fibres and compressive stresses in the matrix which is similar to differential thermal expansion. Secondly, at the molecular level, the diffusing molecules of water may strain or rupture the intermolecular bond in the matrix and at the interface.

4.2. Effect of Thermal Aging. Thermal aging behaviour of composites is of special interest because of their expanding use for structural applications where increased temperatures is a common environmental condition. There are significant chemical and structural changes in epoxy networks which take place during thermal aging. Delamination and microcracking are some of the most frequently observed damaging 
phenomena that may develop in polymer composites exposed to cryogenic temperatures (low temperature conditions). It is important to understand the aging mechanism of polymer composites for their use in thermal environments. The mechanical behaviour of composites depends on the ability of interface to transfer stress from the matrix to the reinforcement fibre. Two batches of samples were fabricated for this test. The first batch of samples was kept in temperature of $+75^{\circ} \mathrm{C}$ (in oven) for 10 hours. And the second batch of samples was similarly exposed to ultra-low deep freezing conditions at $-75^{\circ} \mathrm{C}$ temperature, in the freezer for 6 hours. These were followed by tensile strength testing for both the batches of the samples immediately. It was observed that the tensile strength of woven jute FRP composite increased from 189.48 MPa under unexposed conditions to $197.51 \mathrm{MPa}$ under high temperature, that is, $+75^{\circ} \mathrm{C}$ conditions, and came down to $168.11 \mathrm{MPa}$ under low temperature, that is, $-75^{\circ} \mathrm{C}$ conditions. The most common damage modes in thermal aging are matrix cracking, delamination growth, and fibre fracture. Cryogenic exposure introduces matrix cracking and/or interfacial debonding. During cryogenic conditioning the fibre/matrix adhesion is low. So the first form of damage in laminates is commonly matrix microcracks and interlaminar cracks at such low temperature conditions. This is one of the reasons for the decrease in the tensile strength of composites, when subjected to very low temperatures. Thermal conditioning at higher temperatures imparts better adhesion, and thus an improved tensile strength values are observed, since fibre cross linking is highly probable during thermal conditioning when the composites are exposed to higher temperatures, hence, it increases the tensile strength of the composites.

4.3. Fire Flow Test. From the civil engineering point of view, we are looking towards implementing the FRP composite in old structures or deficient structures as a retrofitting or strengthening material. A fire flow study of any material is very important for the constructional performance, upon studying we can easily know that if any fire-related accident happens, how fast the fire can flow with respect to time considering the building material and how we can reduce the flow rate of fire and what will be the effect in the environment when those particular materials are burnt. This test was performed in accordance to ASTM D635 standard, and the burning rate was measured. It was observed that woven jute FRP composite had a burning rate of $8.1 \mathrm{~mm} / \mathrm{min}$.

\section{Flexural Strengthening of RCC Beams with Woven Jute FRP Composite}

5.1. RCC Beams Specimens. Ordinary Portland cement of 53 grade, conforming to IS: 12269-1987, has been used. Locally available clean river sand have been used in this work. The maximum size of coarse aggregate considered was $12 \mathrm{~mm}$. The coarse aggregate used for the casting of RCC beams passed through $12 \mathrm{~mm}$ IS sieve. As per Indian standard specifications, the mix proportion of the concrete was carried out, in accordance to IS 10262-2009, in order to achieve the desired compressive strength of $20 \mathrm{~N} / \mathrm{mm}^{2}$.
In accordance, the mix proportion by weight of cement: fine aggregate: coarse aggregate was found to be $1: 2.07: 1.87$. The designed water cement ratio was 0.5 . Three numbers of cubes were also cast using the stated mix proportion and water cement ratio, and the average compressive strength for 28 days was $22.309 \mathrm{~N} / \mathrm{mm}^{2}$. Here, Fe 415 HYSD bars of $8 \mathrm{~mm}$ diameter, having characteristic strength of $415 \mathrm{~N} / \mathrm{mm}^{2}$, were used. Three samples of bars were placed in the universal testing machine one after another and were tested for their yield strength. It was found that the bars had average yield strength of $415 \mathrm{~N} / \mathrm{mm}^{2}$. The mentioned bars were both used for the longitudinal reinforcement as well as stirrups. The experimental program contained three beam groups. All the three groups of beams were utilized for the study of the effect of flexural strengthening. All the beams in groups A, B, and $C$ had the same reinforcement detailing, although the beam length for design was $1.3 \mathrm{~m}$, it was cast as $1.4 \mathrm{~m}$, for providing $50 \mathrm{~mm}$ clearance from both the sides at the supports and had a cross section of $140 \mathrm{~mm}$ width and $200 \mathrm{~mm}$ depth. The RCC beam design was carried out as per IS-456: 2000. The entire reinforcement details, which were followed for all the three groups of beams, are shown in Figure 4 . All the beams were designed such that they are strong in shear, so that flexural failure takes place before shear failure, so that the flexural strengthening effect could be evaluated.

5.2. Strengthening Scheme. The beams in group A were designed as controlled specimen (2 number of models, Con1 and Con2), where no FRP application was carried out. The beams in group $\mathrm{B}$ were designed to investigate the effect of full wrapping technique $90^{\circ}$ (3-sided U wrap) for flexural strengthening provided by using woven jute FRP ( 2 number of models, JF1 and JF2). The beams in group C were designed to investigate the effect of strip wrapping technique $90^{\circ}$ (3sided $U$ wrap) where $50 \%$ of the total area was used for strengthening, that is, $62 \mathrm{~mm}$ strips were placed at $124 \mathrm{~mm}$ $\mathrm{C} / \mathrm{C}$ throughout the length of the beam and at a clear gap of $49 \mathrm{~mm}$ at the support ends, for flexural strengthening provided by using woven jute FRP (2 number of models, JF3 and JF4); a summary of the test beams are shown in Table 2. The beams were prepared by grinding 3 side surfaces with the help of a grinding machine, this was done so as to roughen the three sides of the beam where FRP application would be carried out, and roughening the beam surface ensures good boding of the composite material. After grinding, all the three side surfaces of the beams were cleaned with an air nozzle and finally were wiped to remove any dust or loose particles. Small surface defects in the concrete beam were repaired and made good using concresive 2200. Then, a coat of MBrace primer was applied on all the three sides of the beams in group $B$ and C. MBrace primer is a low viscosity, $100 \%$ solids polyamine cured epoxy. It is the first applied component of the MBrace system, and it is used to penetrate the pore structure of cementitous substrates and to provide a high bond base coat for the MBrace system. The primer coat was allowed to air cure for 8 hours. Next, resin Part A and hardener Part $\mathrm{B}$ of the two component MBrace saturant were mechanically premixed as per the guidelines of the manufacturer for 
TABLE 2: Summary of test beams.

\begin{tabular}{|c|c|c|c|c|c|}
\hline Beam group & Wrapping configuration & $\begin{array}{c}\text { Strengthening } \\
\text { material }\end{array}$ & Beam designation & $\begin{array}{c}\text { Type of } \\
\text { strengthening }\end{array}$ & $\begin{array}{c}\text { Strengthening } \\
\text { scheme }\end{array}$ \\
\hline Group A & $\Delta$ & Nil & $\begin{array}{l}\text { Control specimen } \\
\text { Con1, Con } 2\end{array}$ & No strengthening & Nil \\
\hline Group B & $\begin{array}{l}\text { Full wrapping } 90^{\circ} \text {, single layer } \\
\end{array}$ & Jute FRP & JF1, JF2 & $\begin{array}{c}\text { Flexural } \\
\text { strengthening } \\
\text { throughout using } \\
\text { jute FRP } \\
\end{array}$ & $\begin{array}{l}\text { U-Wrap, } \\
\text { three-sided } \\
\text { wrap }\end{array}$ \\
\hline Group C & $\begin{array}{l}\text { Strip wrapping } 90^{\circ} \text {, single layer } 62 \mathrm{~mm} \text { strips } \\
\text { at } 124 \mathrm{~mm} \mathrm{C} / \mathrm{C} \text { (at a clear gap of } 62 \mathrm{~mm} \text { ) so } \\
\text { as to achieve } 50 \% \text { of total area strengthening, } \\
\text { with end clear gaps of } 49 \mathrm{~mm} \text {. }\end{array}$ & Jute FRP & JF3, JF4 & $\begin{array}{c}\text { Flexural } \\
\text { strengthening } \\
\text { throughout using } \\
\text { jute FRP }\end{array}$ & $\begin{array}{l}\text { U-Wrap, } \\
\text { three-sided } \\
\text { wrap }\end{array}$ \\
\hline
\end{tabular}
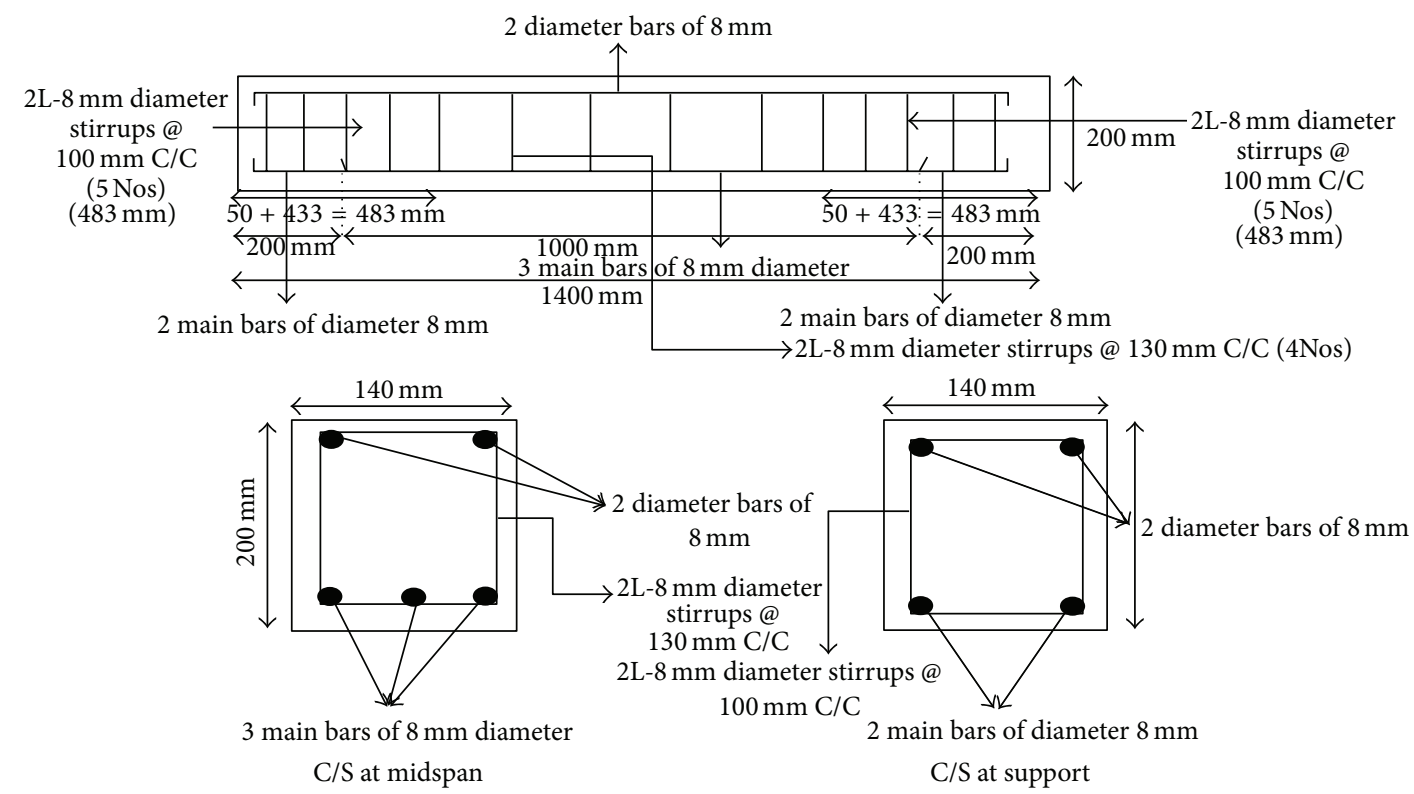

FIGURE 4: Reinforcement detailing of RCC beams (all sets, group A, B, and C).

3 minutes or until homogeneousness. The property of the MBrace saturant as provided by the manufacturer is given in Table 3. The ratio of mixing of resin and hardener was followed as per the manufacturer, which stood to be $3: 1$. Then the neatly measured and cut pieces of woven jute fibres were correspondingly applied on the respected beams JF1, JF2, JF3, and JF4. The woven jute fibres were placed on top of epoxy resin coating immediately on the respective beams, and the resin was squeezed through the roving of the fabric with plastic laminating roller. It was made sure that all the woven jute fibre reinforcements are properly impregnated in the resin hardener mix, and lastly one more coat of epoxyhardener mix was applied on top of the woven jute fibres on all the respective beams, as a finishing layer. Air bubbles entrapped at the epoxy/concrete or epoxy/fibre interface were eliminated. All the strengthened concrete beams were cured for at least two weeks at room temperature before the beams
TABLE 3: Typical properties of MBrace Saturant.

\begin{tabular}{|c|c|}
\hline Mechanical property & MBrace Saturant \\
\hline Description & $\begin{array}{l}2 \text { parts; Part A: epoxy and Part B: } \\
\text { hardener }\end{array}$ \\
\hline Density & $1.06 \mathrm{~kg} / \mathrm{Lt}$ (Mixed density) \\
\hline Colour & Blue \\
\hline Bond strength & $>2.5 \mathrm{~N} / \mathrm{mm}^{2}$ (Failure in concrete) \\
\hline
\end{tabular}

were tested. The entire strengthening process is demonstrated in Figure 5.

5.3. Test Setup. A third point loading system was adopted for the beam tests. At the end of each load increment, deflection, ultimate load, type of failure, and so forth were carefully observed and recorded. The experimental set-up under 


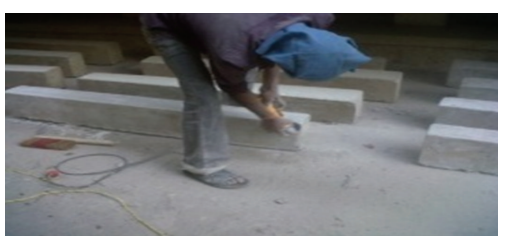

(a)

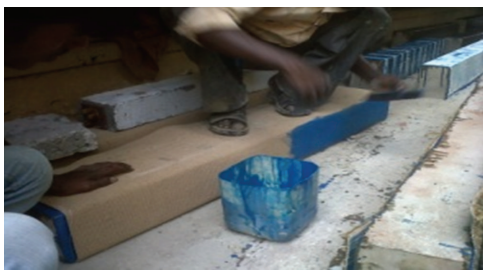

(d)

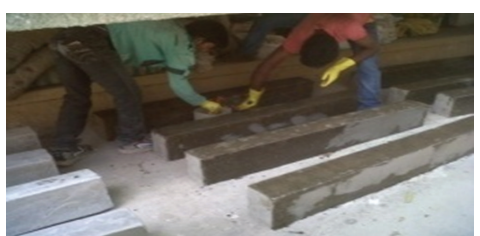

(b)

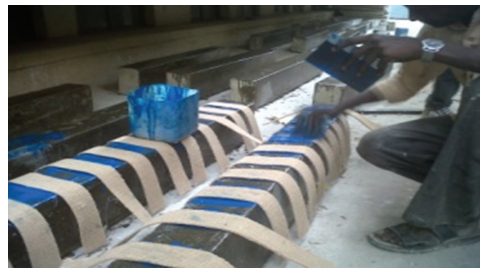

(e)

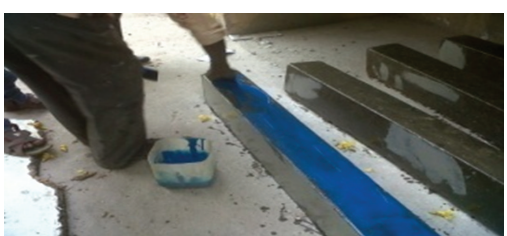

(c)

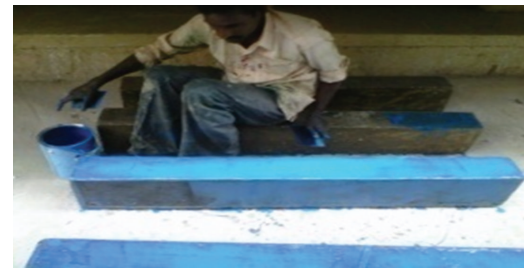

(f)

FIGURE 5: (a) Surface preparation of beams by grinding; (b) primer application on beam surface; (c) application of epoxy-hardener mix on the beam; (d) bonding of woven jute; (e) bonding of woven jute in strips; (f) final coating of epoxy-hardener mix on the bonded fabric.

the third point loading system is shown in Figure 6. All the three sets of beams under group A, B, and C were tested to find out their ultimate flexural strengths, and the deflection at the centre were noted.

5.4. Results and Discussions. The ultimate load carrying capacity, that is, the ultimate flexural strength of all the beams along with the nature of failure and deflections, are given in Table 4. The flexural fractures and cracks of all the beam specimens are as demonstrated in various subparts of Figure 7. Load deflection curves for strengthened beams along with control specimens are as shown in Figure 8, and the comparisons of the ultimate flexural strength of all the beams along with the comparison of the first crack loads are represented in Figure 9. The various failure modes along with the load deflection behavior and the ultimate flexural strength of the controlled beams and the strengthened beams are discussed below.

5.4.1. Failure Modes and Flexural Strength Study of Controlled Beams. The first set of beam, that is, group A and Conl and Con2, failed in flexure which proved that the beams were strong in shear, and henceforth flexural failure took place before shear failure. Major vertical cracks developed in the midspan that is, in the pure flexure zone, these cracks firstly developed at the lower face, that is, at the bottom side of the beam, and extended from the bottom side towards the top face of the beam. Both the beams Con1 and Con2 failed in similar manner, and Figure 7(a) depicts the clear representation of the failure of group A beams. The average ultimate flexural strength of group A beams was $80 \mathrm{KN}$.

5.4.2. Failure Modes and Flexural Strength Study of Fully $U$ Wrapped Beams. In the second set of beams in group B, in which the beams were strengthened by fully $U$ wrapped woven jute FRP, JF1, and JF2, it was seen that both beams failed in flexure and their flexural strength was much higher than that of Group A beams. When load was applied on JF1 and JF2, firstly the matrix started cracking, then on further increment of load, the jute fibres in jute FRP started to crack, then again on further load increment the cracks in jute FRP started to widen, then the RCC beam showed vertical crack in the flexure zone, and then this crack started to slowly move from the bottom side of the beam to the top side. Both the failure modes depicted in JF1 and JF2 were very ductile in nature, and the beam carried huge deflection. There was no debonding of jute FRP at all from the beam face in any direction even at very high load, and hence cracks were visualized only on the woven jute FRO and not on the RCC beam. Only a single crack appeared in JF1 on the woven jute FRP, and this crack started to widen with the increase in the load, without the development of any other cracks. The widening of this crack showed and exposed the crack in the RCC beam, at the same location. In the other beam JF2, two cracks appeared on the woven jute FRP which started to widen with the increase in the load, without the development of any other cracks, and the widening of the two cracks exposed the cracks in the RCC beam at the same locations. All the cracks observed in both the beams JF1 and JF2 were at the beam flexure zone, and the ultimate flexural load was reached by further widening of these cracks, without the generation of any other alternate cracks. The average ultimate strength of group B beams JF1 and JF2 was $130 \mathrm{KN}$. Both the beams JF1 and JF2 failed in similar manner. Figure 7(b) depicts the clear representation of the failure mode of JF1, and Figure 7(c) depicts that of JF2.

\subsubsection{Failure Modes and Flexural Strength Study of Partially $U$} Wrapped Beams. The third set of beams in group C, in which the beams were strengthened by strips, that is, $U$ wrapped woven jute FRP in strips, JF3 and JF4, and all strip wrapped strengthened beams were tested to find out their ultimate flexural strength. It was seen that the beams JF3 and JF4 showed higher ultimate load carrying capacity than that of group A beams, but lower than that of group B beams. In the group $\mathrm{C}$ beams, it was observed that cracks first developed 


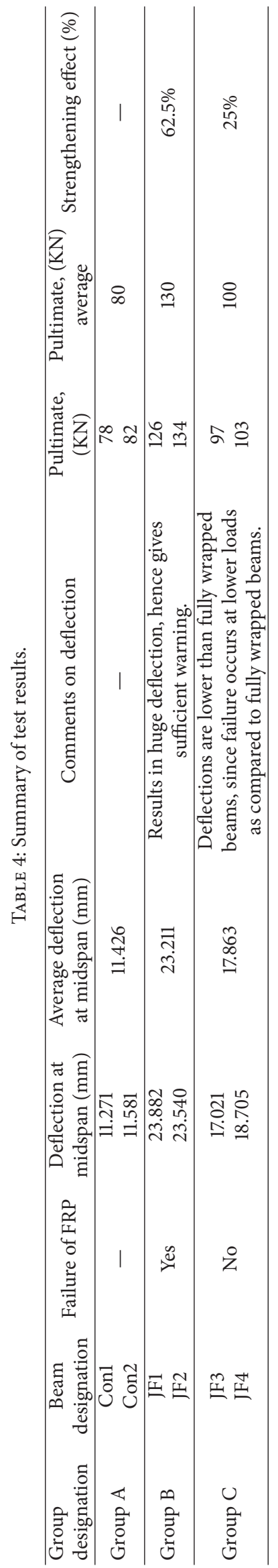




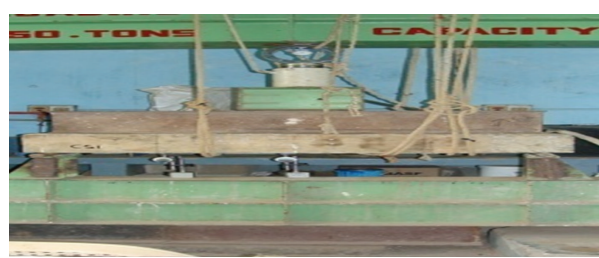

(a)

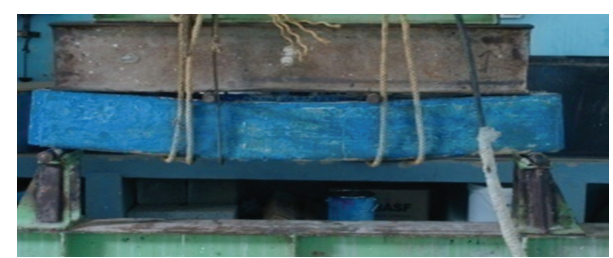

(b)

FIGURE 6: (a) Two pint loading system on a 50 ton loading frame; (b) loading on fully wrapped beam with woven jute FRP.

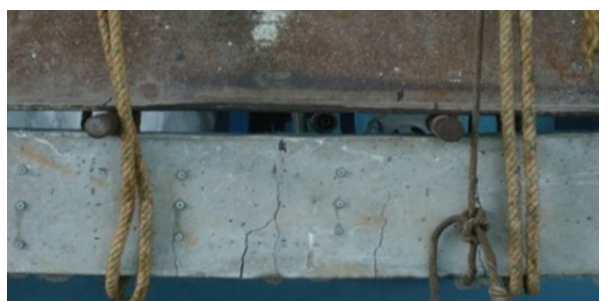

(a)

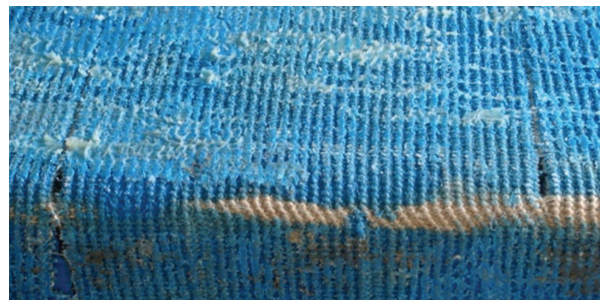

(c)

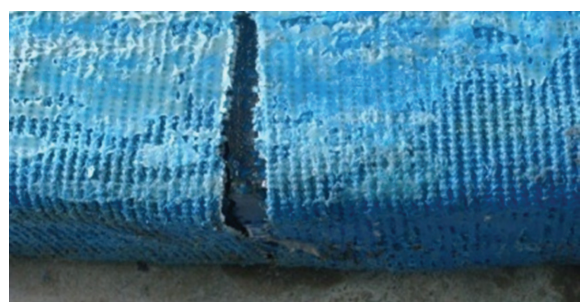

(b)

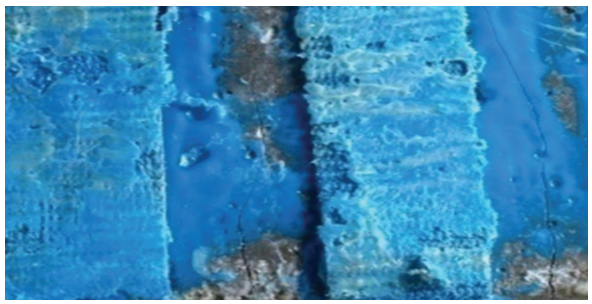

(d)

Figure 7: (a) Control beams (group A, Con1) under load; (b) formation of flexure crack in the beam JF1, under load; (c) formation of flexure crack in the beam JF2, under load; (d) formation of flexure crack in the beam JF3, under load.

in the RCC beams, that is, on the concrete surface only, and not on the woven jute FRP composite; this indicated that the presence of bonded woven jute FRP on RCC beams imparted additional strength to the beams, and thereby enhanced their flexural strength as compared to controlled beams. When load was applied on JF3 and JF4, then major vertical cracks developed in the mid span that is, in the pure flexure zone, and these cracks developed only in the beam area, and a single flexural crack did not develop on the FRP nor did the FRP undergo rupture or debonding, these cracks on the beam firstly developed at the lower face, that is, beam bottom face, and extended from the bottom side towards the top face of the beam. The strip wrapping technique of FRP strengthening increased the ultimate load carrying capacity up to a point which lied between the load carrying capacity increased by that of full wrapping technique and the unstrengthened, that is, controlled beams. The failure modes of beams JF3 is depicted in Figure 7(d), which clearly shows the flexural cracks in all the beams. The average ultimate strength of group C beams JF3 and JF4 was $100 \mathrm{KN}$.

\section{Conclusions}

The following conclusions can be drawn from the study.

(1) The woven jute FRP composite which was mechanically subjected to heat has shown highest tensile strength of
189.479 N/mm ${ }^{2}$ and tensile modulus of $32500 \mathrm{~N} / \mathrm{mm}^{2}$, which is the highest tensile strength value, obtained from all the pretreatment procedures used for pretreating the woven jute, and is also higher as compared to controlled samples of woven jute FRP, where no treatment was carried out.

(2) Similarly, the woven jute FRP composite which was mechanically subjected to heat has shown the highest flexural strength of $208.705 \mathrm{~N} / \mathrm{mm}^{2}$ and flexural modulus of $4500 \mathrm{~N} / \mathrm{mm}^{2}$, which is the highest flexural strength value, obtained from all the pretreatment procedures used for pretreating the woven jute, and is also higher as compared to controlled samples of woven jute FRP, where no treatment was carried out.

(3) It was observed that the composites of woven jute FRP, which was untreated or control specimen along with the heat treated woven jute FRP composite, displayed highest tensile and flexural strength, that is, superior mechanical properties, as compared to both the chemically treated, that is, alkali treated or benzylated woven jute FRP composite samples. The reason for this lies in the fact that, we are hereby using woven yarns of jute (not loose jute fibres), chemical treatment results in, partial unwinding of yarns (as hemicellulose dissolves off) and hence the alignment of the fibres gets antagonized. This results in, lowering of strength of woven or textile composites, when subjected to chemical treatment. Another reason is that as woven jute 


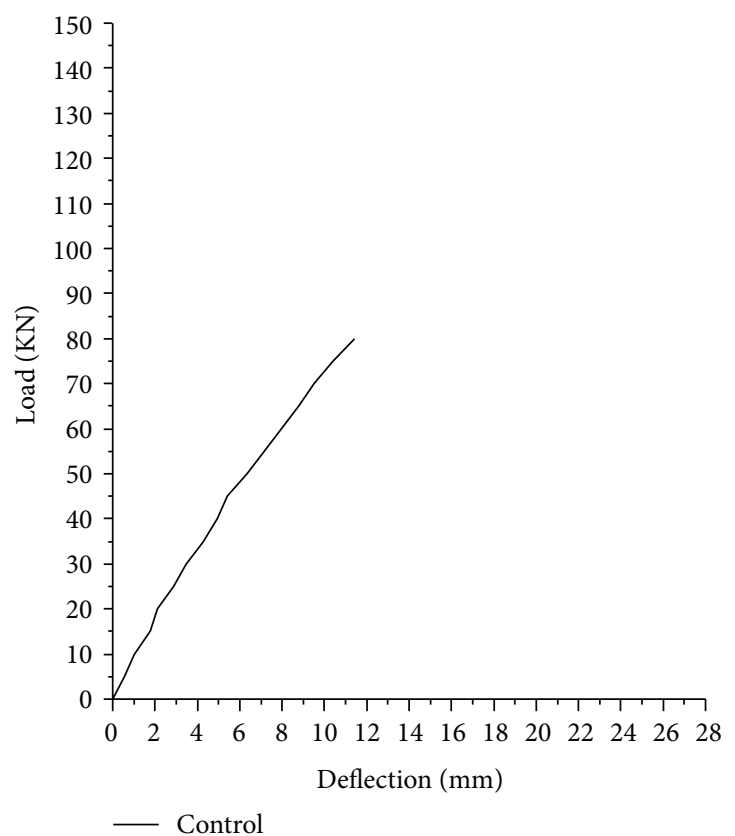

(a)

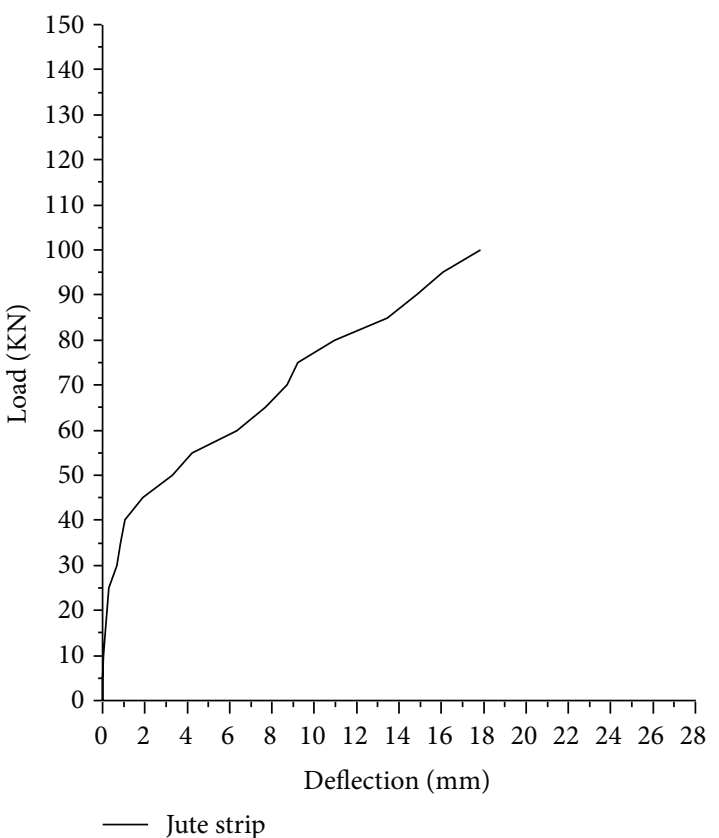

(b)

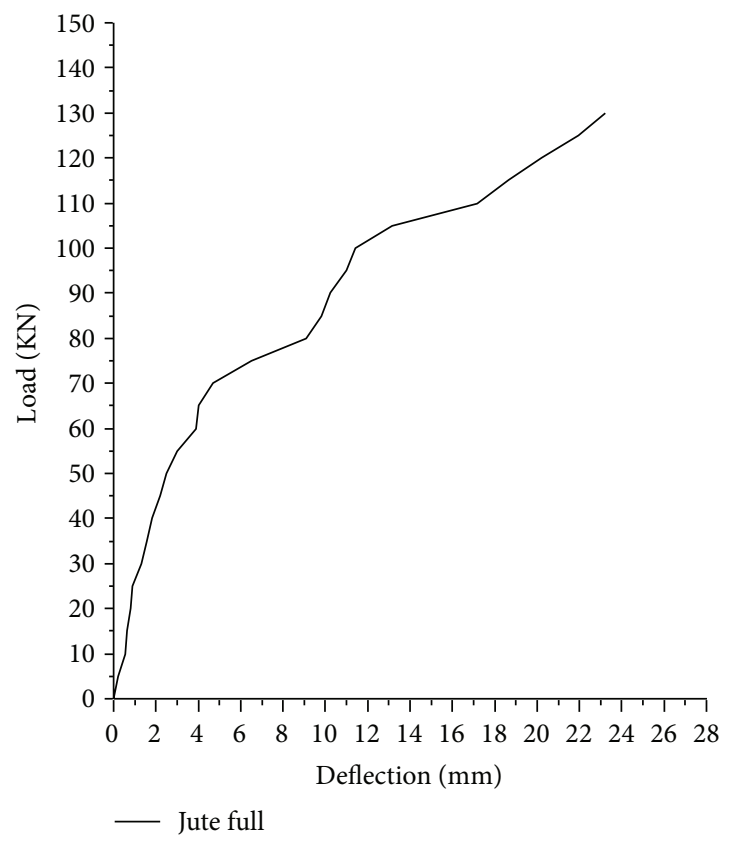

(c)

FIGURE 8: Load versus midspan deflection of (a) Control; (b) woven jute FRP strip wrapped beams; (c) woven jute FRP fully wrapped beams.

is composed of thick strands and knots of the fibres, the alkali and benzyl chloride agents do not penetrate the fabric or textile uniformly, and therefore the interfacial properties between the woven jute and the matrix does get improved enough. The lower strength properties of the composites containing alkali treated as well as benzylated woven jute fibres because of the result of nonuniform penetration of chemicals within the thick strands of the fabric or textile. It can be seen that the highest values are exhibited by thermally treated composites. This could be attributed to the fact that upon continuous heat treatment, the crystallinity of cellulose increases due to the rearrangement of molecular structure at elevated temperatures. The thermal treatment also resulted in moisture loss of the woven jute, thereby enhancing the extent of bonding between woven jute and the matrix.

(4) It can also be concluded that the heat treatment process which aids in the demoisturisation of fibres is a better treatment method as compared to any other chemical treatment method for improving mechanical properties of natural fibre woven or textile composites. Thermally treated 


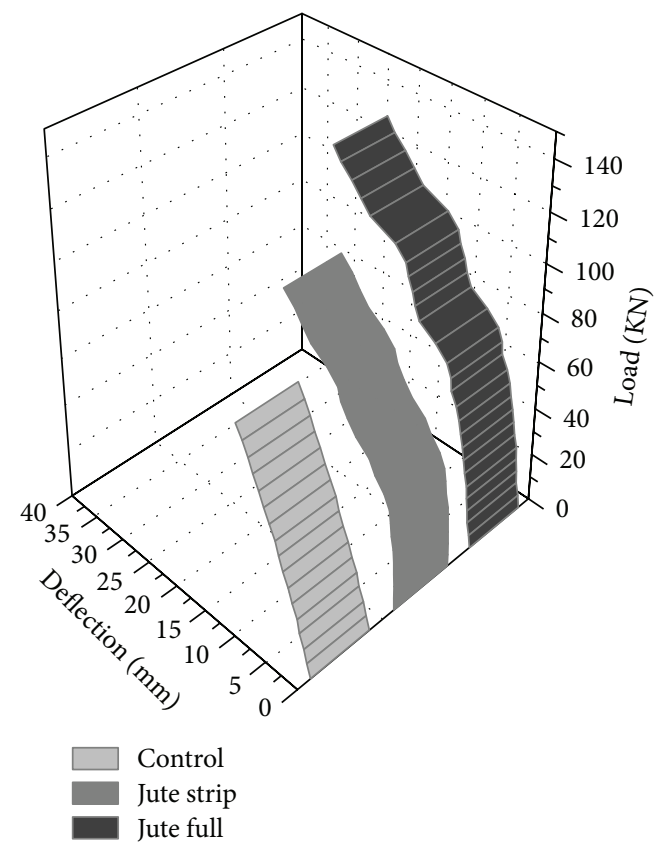

(a)

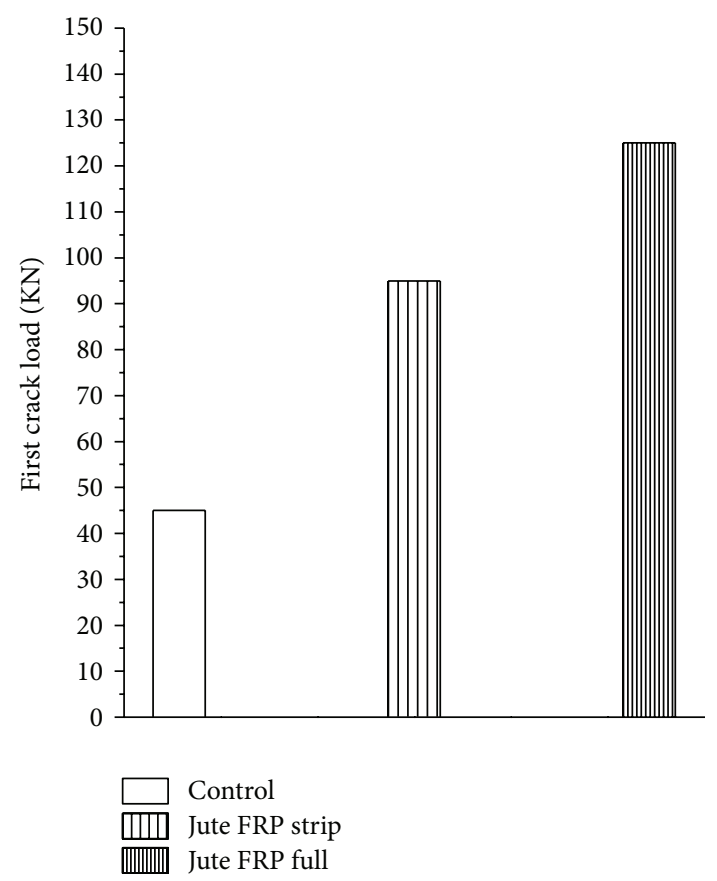

(b)

FIGURE 9: (a) Comparison of ultimate load carrying capacity of all beams; (b) comparison of first crack load of all beams.

composites exhibited superior mechanical properties, both in terms of tensile strength and flexural strength because of increased crystallinity.

(5) From the durability study based on the effect of normal water on woven jute FRP, it could be concluded that woven jute FRP composites behaved similarly to artificial FRP composites of glass and carbon, that is, ultimate tensile strength of wet samples were higher than that for dry samples. This could be attributed to the fact that high amounts of water causes swelling of the fibres, which fills the gaps between the fibre and the polymer-matrix and eventually leads to an increase in the mechanical properties of the fibre composites, but the percentage of moisture absorption and thickness swelling of woven jute FRP composites were slightly on the higher side as compared to artificial FRP composites.

(6) From the durability study based on the effect of thermal aging on woven jute FRP, it could be concluded that woven jute FRP composites behaved similarly to artificial FRP composites of glass and carbon, that is, ultimate tensile strength under cryogenic exposure was lower, and ultimate tensile strength under higher temperature conditioning was higher.

(7) The work being done in this study is important to the composites industry because it is a beginning of systematic research into how the fibre type and also the content affect the overall fire performance of the composites. The burning rate of jute FRP was substantially lower than the burning rate of other artificial FRP composites.

(8) The application of woven jute FRP sheets showed a better performance in increasing the ultimate flexural strength capacity of RC beams as compared to the controlled
RC beams. Maximum ultimate load of $126 \mathrm{KN}$ and $134 \mathrm{KN}$ was carried, respectively, by the beams JF1 and JF2, when full U wrapping technique was used, whereas the controlled RCC beams failed at an average ultimate load of $80 \mathrm{KN}$. Thus, we can conclude that flexural strengthening of RCC beams can be achieved by the use of woven jute FRP composites.

(9) In the beams, JF1 and JF2, the strengthening effect was very noteworthy with one layer itself, providing an increase in the flexural strength by $62.5 \%$, and woven jute FRP bonding also promoted ductile failure without any concrete crushing or FRP rupture or any debonding of FRP, even at very high loads. Hence with increasing the number of layers of jute FRP, a more significant strength improvement could be attained in the flexural strength.

(10) Increase in the ultimate flexural strength of beams by $25 \%$, with woven jute FRP in strips, was observed for beams belonging to group $\mathrm{C}$, where the strip wrapping technique was followed. The presence of strips delayed the first crack formation at locations where FRP was bonded to the beams. By the use of natural jute FRP in the strengthened beams, the initial cracks were formed at higher loads than their respective control beams. This showed that the use of natural woven FRP is very effective in the case of flexural strengthening of structures.

(11) The ultimate strength of beams could be increased by the use of natural woven jute FRP, being bonded to the beam in full length or being bonded in strips. The ultimate flexural loads of beams strengthened with $U$ full wrapping were greater than the beams strengthened by bonding using strip wrapping. Increase in strength depends on the width of the strip that was bonded to the beam. 
(12) The load deflection behavior was better for beams strengthened with woven jute FRP compared to the controlled beams. Woven jute FRP strengthened beams in full length depicted typical ductile failure and carried large deflections before undergoing failure and totally avoided any mode of catastrophic failure of beams.

(13) Natural woven fibres of jute FRP have great potential in increasing the load carrying capacity of RCC beams, and also enhanced the material efficiency. Hence, the woven jute FRP can be regarded as a suitable strengthening material for flexural strengthening of concrete structures particularly, and as a good alternative methodology among the fabric reinforcement in FRP considering economic and environmental aspects of FRP products.

\section{Acknowledgments}

The authors acknowledge the support extended to the work by various undergraduate and postgraduate students working under the guidance of the authors and also laboratory supporting staff members and the laboratory assistants.

\section{References}

[1] K.-T. Lau and L.-M. Zhou, "Mechanical performance of composite-strengthened concrete structures," Composites B, vol. 32, no. 1, pp. 21-31, 2001.

[2] S. A. Sheikh, "Performance of concrete structures retrofitted with fibre reinforced polymers," Engineering Structures, vol. 24, no. 7, pp. 869-879, 2002.

[3] F. Ceroni, "Experimental performances of RC beams strengthened with FRP materials," Construction and Building Materials, vol. 24, no. 9, pp. 1547-1559, 2010.

[4] J. Dong, Q. Wang, and Z. Guan, "Structural behaviour of RC beams with external flexural and flexural-shear strengthening by FRP sheets," Composites B, vol. 44, no. 1, pp. 604-612, 2013.

[5] R. Al-Amery and R. Al-Mahaidi, "Coupled flexural-shear retrofitting of RC beams using CFRP straps," Composite Structures, vol. 75, no. 1-4, pp. 457-464, 2006.

[6] J. A. O. Barros, S. J. E. Dias, and J. L. T. Lima, "Efficacy of CFRPbased techniques for the flexural and shear strengthening of concrete beams," Cement \& Concrete Composites, vol. 29, no. 3, pp. 203-217, 2007.

[7] A. A. El-Ghandour, "Experimental and analytical investigation of CFRP flexural and shear strengthening efficiencies of RC beams," Construction and Building Materials, vol. 25, no. 3, pp. 1419-1429, 2011.

[8] M. R. Esfahani, M. R. Kianoush, and A. R. Tajari, "Flexural behaviour of reinforced concrete beams strengthened by CFRP sheets," Engineering Structures, vol. 29, no. 10, pp. 2428-2444, 2007.

[9] S. Hashemi and R. Al-Mahaidi, "Flexural performance of CFRP textile-retrofitted RC beams using cement-based adhesives at high temperature," Construction and Building Materials, vol. 28, no. 1, pp. 791-797, 2012.

[10] J. R. Correia, F. A. Branco, and J. G. Ferreira, "Flexural behaviour of GFRP-concrete hybrid beams with interconnection slip," Composite Structures, vol. 77, no. 1, pp. 66-78, 2007.
[11] T. H. Almusallam, "Load-deflection behavior of RC beams strengthened with GFRP sheets subjected to different environmental conditions," Cement and Concrete Composites, vol. 28, no. 10, pp. 879-889, 2006.

[12] J. R. Correia, L. Valarinho, and F. A. Branco, "Post-cracking strength and ductility of glass-GFRP composite beams," Composite Structures, vol. 93, no. 9, pp. 2299-2309, 2011.

[13] S. V. Joshi, L. T. Drzal, A. K. Mohanty, and S. Arora, "Are natural fiber composites environmentally superior to glass fiber reinforced composites?" Composites A, vol. 35, no. 3, pp. 371$376,2004$.

[14] J. Summerscales, N. Dissanayake, A. Virk, and W. Hall, "A review of bast fibres and their composites. Part 2-composites," Composites A, vol. 41, no. 10, pp. 1336-1344, 2010.

[15] V. K. Mathur, "Composite materials from local resources," Construction and Building Materials, vol. 20, no. 7, pp. 470-477, 2006.

[16] A. C. Milanese, M. O. H. Cioffi, and H. J. C. Voorwald, "Mechanical behavior of natural fibre composites," Procedia Engineering, vol. 10, pp. 2022-2027, 2011.

[17] G. Koronis, A. Silva, and M. Fontul, "Green composites: a review of adequate materials for automotive applications," Composites B, vol. 44, no. 1, pp. 120-127, 2013.

[18] A. K. Bledzki and J. Gassan, "Composites reinforced with cellulose based fibres," Progress in Polymer Science, vol. 24, no. 2, pp. 221-274, 1999.

[19] K. G. Satyanarayana, G. G. C. Arizaga, and F. Wypych, "Biodegradable composites based on lignocellulosic fibers-an overview," Progress in Polymer Science, vol. 34, no. 9, pp. 9821021, 2009.

[20] M. Q. Zhang, M. Z. Rong, and X. Lu, "Fully biodegradable natural fiber composites from renewable resources: all-plant fiber composites," Composites Science and Technology, vol. 65, no. 15-16, pp. 2514-2525, 2005.

[21] T. Munikenche Gowda, A. C. B. Naidu, and R. Chhaya, "Some mechanical properties of untreated jute fabric-reinforced polyester composites," Composites A, vol. 30, no. 3, pp. 277-284, 1999.

[22] J. Gassan and A. K. Bledzki, "Possibilities for improving the mechanical properties of jute/epoxy composites by alkali treatment of fibres," Composites Science and Technology, vol. 59, no. 9, pp. 1303-1309, 1999.

[23] J. Gassan and A. K. Bledzki, "Alkali treatment of jute fibers: relationship between structure and mechanical properties," Journal of Applied Polymer Science, vol. 71, no. 4, pp. 623-629, 1999.

[24] A. Stocchi, B. Lauke, A. Vázquez, and C. Bernal, "A novel fiber treatment applied to woven jute fabric/vinylester laminates," Composites A, vol. 38, no. 5, pp. 1337-1343, 2007.

[25] W.-M. Wang, Z.-S. Cai, and J.-Y. Yu, "Study on the chemical modification process of jute fiber," Journal of Engineered Fibers and Fabrics, vol. 3, no. 2, pp. 1-11, 2010.

[26] X. Y. Liu and G. C. Dai, "Surface modification and micromechanical properties of jute fiber mat reinforced polypropylene composites," Express Polymer Letters, vol. 1, no. 5, pp. 299-307, 2007.

[27] C.-H. Chen, C.-Y. Chen, Y.-W. Lo, C.-F. Mao, and W.-T. Liao, "Characterization of alkali-treated jute fibers for physical and mechanical properties," Journal of Applied Polymer Science, vol. 80, no. 7, pp. 1013-1020, 2001. 
[28] M. Jawaid, H. P. S. Abdul Khalil, and A. Abu Bakar, "Woven hybrid composites: tensile and flexural properties of oil palmwoven jute fibres based epoxy composites," Materials Science and Engineering A, vol. 528, no. 15, pp. 5190-5195, 2011.

[29] K. S. Ahmed and S. Vijayarangan, "Tensile, flexural and interlaminar shear properties of woven jute and jute-glass fabric reinforced polyester composites," Journal of Materials Processing Technology, vol. 207, no. 1-3, pp. 330-335, 2008.

[30] P. Sudhakara, D. Jagadeesh, Y. Wang et al., "Fabrication of Borassus fruit lignocellulose fibre/PP composites and comparison with jute, sisal and coir fibres," Carbohydrate Polymers, vol. 98, no. 1, pp. 1002-1010, 2013.

[31] M. S. Meon, M. F. Othman, H. Husain, M. F. Remeli, and M. S. M. Syawal, "Improving tensile properties of kenaf fibres treated with Sodium hydroxide," Procedia Engineering, vol. 41, pp. 15871592, 2012.

[32] O. M. L. Asumani, R. G. Reid, and R. Paskaramoorthy, "The effects of alkali-silane treatment on the tensile and flexural properties of short fibre non-woven kenaf reinforced polypropylene composites," Composites A, vol. 43, no. 9, pp. 1431-1440, 2012.

[33] S. Ochi, "Mechanical properties of kenaf fibers and kenaf/PLA composites," Mechanics of Materials, vol. 40, no. 4-5, pp. 446452, 2008.

[34] S. Shibata, Y. Cao, and I. Fukumoto, "Lightweight laminate composites made from kenaf and polypropylene fibres," Polymer Testing, vol. 25, no. 2, pp. 142-148, 2006.

[35] B. F. Yousif, A. Shalwan, C. W. Chin, and K. C. Ming, "Flexural properties of treated and untreated kenaf/epoxy composites," Materials and Design, vol. 40, pp. 378-385, 2012.

[36] H. Deka, M. Misra, and A. Mohanty, "Renewable resource based "all green composites" from kenaf biofiber and poly(furfuryl alcohol) bioresin," Industrial Crops and Products, vol. 41, pp. 94101, 2012.

[37] M. Ramesh, K. Palanikumar, and K. H. Reddy, "Comparative evaluation on properties of hybrid glass fiber-sisal/jute reinforced epoxy composites," Procedia Engineering, vol. 51, pp. 745750, 2013.

[38] M. Ramesh, K. Palanikumar, and K. H. Reddy, "Comparative evaluation on properties of hybrid glass fiber-sisal/jute reinforced epoxy composites," in Proceedings of the 3rd Nirma University International Conference on Chemical, Civil and Mechanical Engineering Tracks (NUiCONE '12), Nirma University, Ahmedabad, India, December 2012.

[39] K. Mylsamy and I. Rajendran, "The mechanical properties, deformation and thermomechanical properties of alkali treated and untreated Agave continuous fibre reinforced epoxy composites," Materials and Design, vol. 32, no. 5, pp. 3076-3084, 2011.

[40] F. D. A. Silva, R. D. T. Filho, J. D. A. M. Filho, and E. D. M. R. Fairbairn, "Physical and mechanical properties of durable sisal fiber-cement composites," Construction and Building Materials, vol. 24, no. 5, pp. 777-785, 2010.

[41] M. Ramesh, K. Palanikumar, and K. H. Reddy, "Mechanical property evaluation of sisal-jute-glass fiber reinforced polyester composites," Composites B, no. 48, pp. 1-9, 2013.

[42] A. Kalam, B. B. Sahari, Y. A. Khalid, and S. V. Wong, "Fatigue behaviour of oil palm fruit bunch fibre/epoxy and carbon fibre/epoxy composites," Composite Structures, vol. 71, no. 1, pp. 34-44, 2005.

[43] A. A. Mamun, H.-P. Heim, D. H. Beg, T. S. Kim, and S. H. Ahmad, "PLA and PP composites with enzyme modified oil palm fibre: a comparative study," Composites A, vol. 53, pp. 160167, 2013.

[44] M. M. Haque, M. Hasan, M. S. Islam, and M. E. Ali, "Physicomechanical properties of chemically treated palm and coir fiber reinforced polypropylene composites," Bioresource Technology, vol. 100, no. 20, pp. 4903-4906, 2009.

[45] M. Jawaid, H. P. S. Abdul Khalil, A. Hassan, R. Dungani, and A. Hadiyane, "Effect of jute fibre loading on tensile and dynamic mechanical properties of oil palm epoxy composites," Composites B, vol. 45, no. 1, pp. 619-624, 2013.

[46] A. Alawar, A. M. Hamed, and K. Al-Kaabi, "Characterization of treated date palm tree fiber as composite reinforcement," Composites B, vol. 40, no. 7, pp. 601-606, 2009.

[47] T. Yu, J. Ren, S. Li, H. Yuan, and Y. Li, "Effect of fiber surface-treatments on the properties of poly(lactic acid)/ramie composites," Composites A, vol. 41, no. 4, pp. 499-505, 2010.

[48] C. Z. P. Júnior, L. H. de Carvalho, V. M. Fonseca, S. N. Monteiro, and J. R. M. d'Almeida, "Analysis of the tensile strength of polyester/hybrid ramie-cotton fabric composites," Polymer Testing, vol. 23, no. 2, pp. 131-135, 2004.

[49] S. Harish, D. P. Michael, A. Bensely, D. M. Lal, and A. Rajadurai, "Mechanical property evaluation of natural fiber coir composite," Materials Characterization, vol. 60, no. 1, pp. 44-49, 2009.

[50] N. Defoirdt, S. Biswas, L. D. Vriese et al., "Assessment of the tensile properties of coir, bamboo and jute fibre," Composites A, vol. 41, no. 5, pp. 588-595, 2010.

[51] F. I. Romli, A. N. Alias, A. S. M. Rafie, and D. L. A. Abdul Majid, "Factorial study on the tensile strength of a coir fibre-reinforced epoxy composite," AASRI Procedia, vol. 3, pp. 242-247, 2012.

[52] C. Asasutjarit, S. Charoenvai, J. Hirunlabh, and J. Khedari, "Materials and mechanical properties of pretreated coir-based green composites," Composites B, vol. 40, no. 7, pp. 633-637, 2009.

[53] N. G. Jústiz-Smith, G. J. Virgo, and V. E. Buchanan, "Potential of Jamaican banana, coconut coir and bagasse fibres as composite materials," Materials Characterization, vol. 59, no. 9, pp. 12731278, 2008.

[54] M. M. Rahman and M. A. Khan, "Surface treatment of coir (Cocos nucifera) fibers and its influence on the fibers' physicomechanical properties," Composites Science and Technology, vol. 67, no. 11-12, pp. 2369-2376, 2007.

[55] V. M. Karbhari, J. W. Chin, D. Hunston et al., "Durability gap analysis for fiber-reinforced polymer composites in civil engineering," Journal of Composites for Construction, vol. 7, no. 3, pp. 238-247, 2003. 

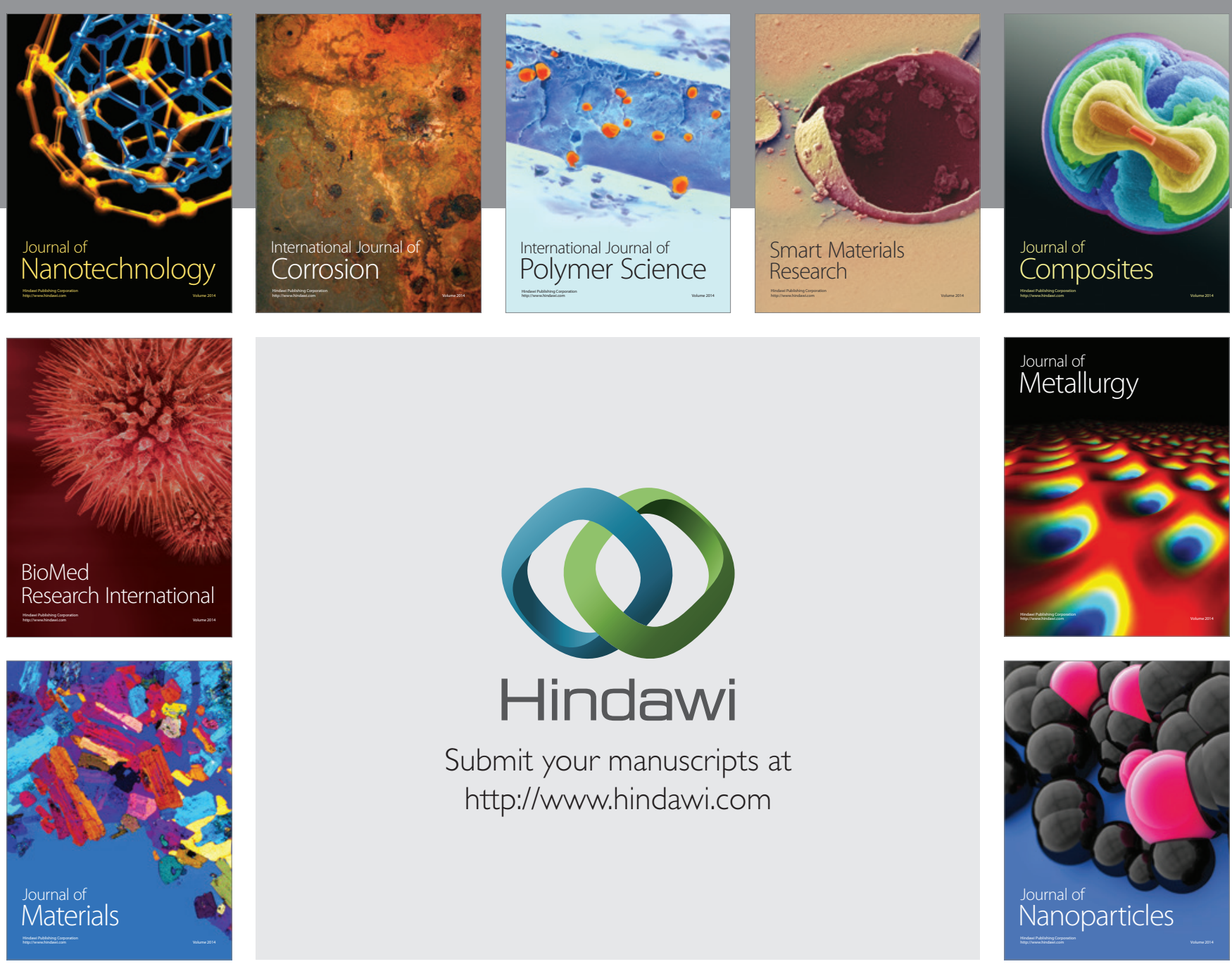

Submit your manuscripts at http://www.hindawi.com
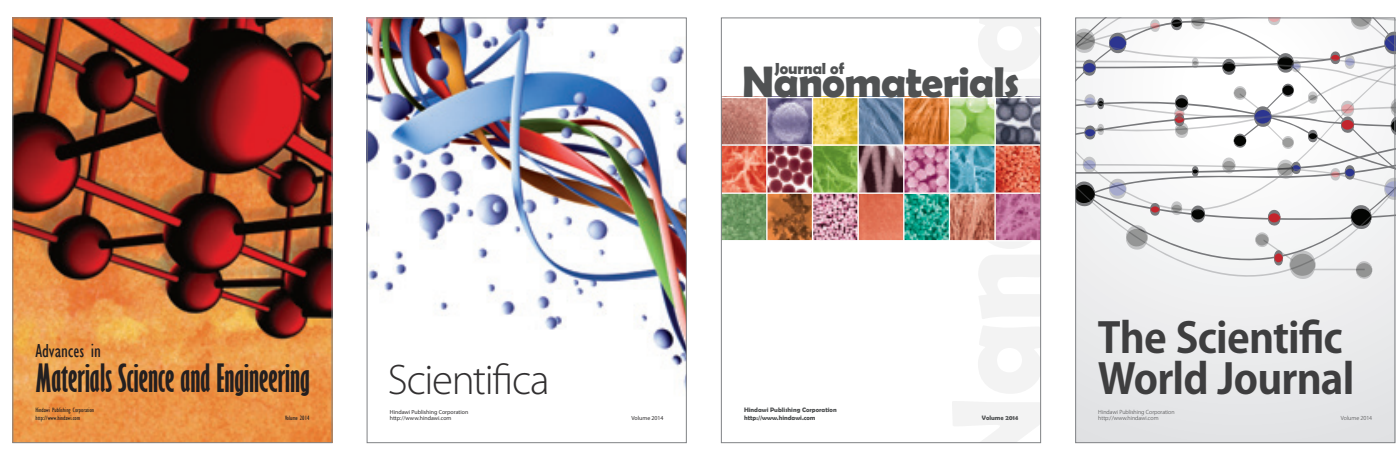

\section{The Scientific World Journal}
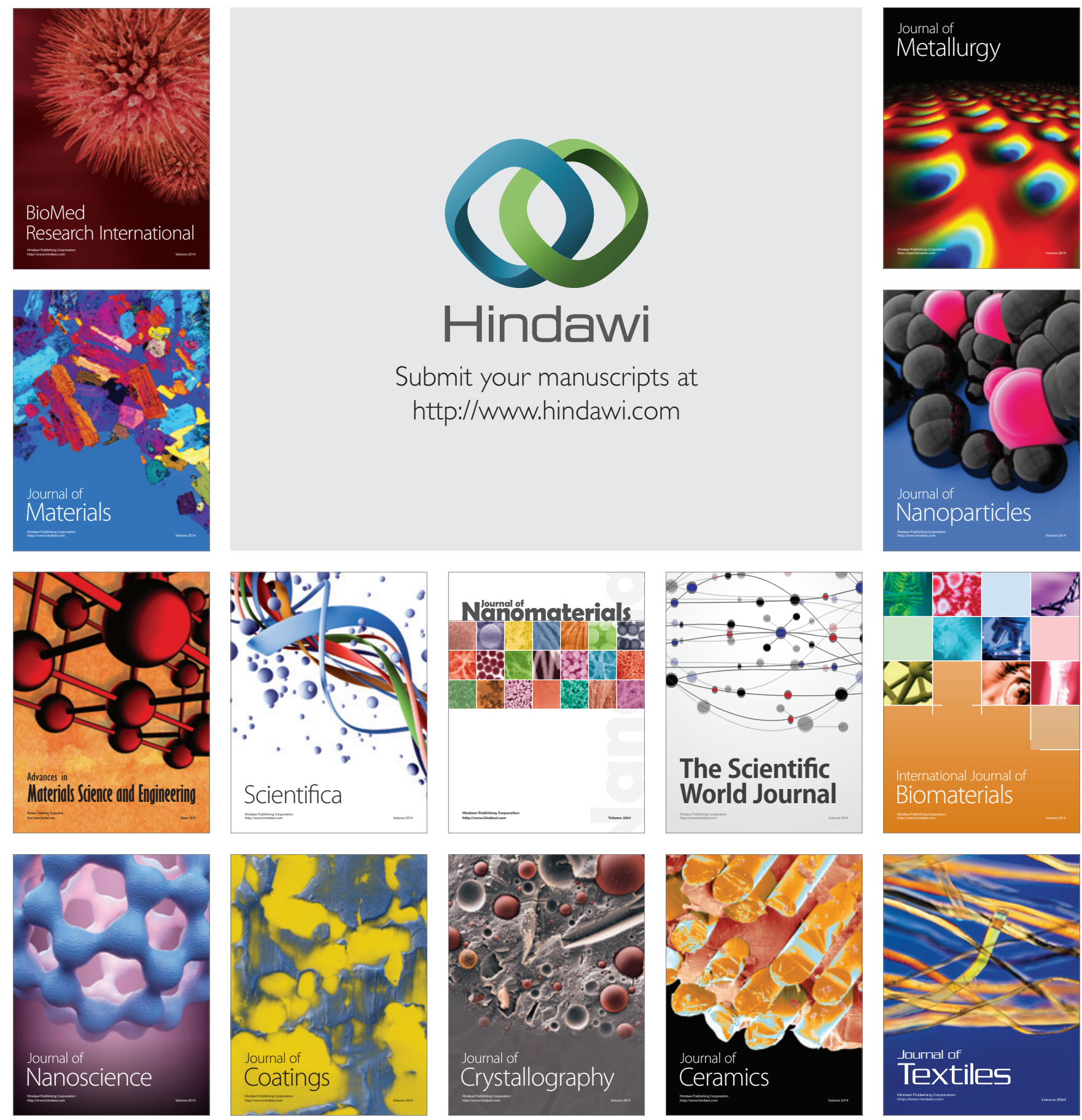